\title{
Early contribution of phonological awareness and later influence of phonological memory throughout reading acquisition
}

\author{
Christelle Nithart, Elisabeth Demont and \\ Marie-Noëlle Metz-Lutz \\ Université de Strasbourg, France
}

Steve Majerus and Martine Poncelet

University of Liege, Belgium

Jacqueline Leybaert

Université Libre de Bruxelles, Belgium

\begin{abstract}
The acquisition of reading skills is known to rely on early phonological abilities, but only a few studies have investigated the independent contribution of the different steps involved in phonological processing. This 1-year longitudinal study, spanning the initial year of reading instruction, aimed at specifying the development of phonological discrimination, awareness and various aspects of phonological memory and at assessing their respective contributions to early reading acquisition. Our results show an increase in performance at each phonological processing step, but also suggest a qualitative evolution in their relative importance. Hierarchical regression analyses indicate that reading skills are mainly predicted by phonological awareness measured at the kindergarten stage and, subsequently, by phonological memory abilities measured at the end of first grade. More precisely short-term memory for serial-order information seems to contribute to the development of decoding abilities, while phonological knowledge stored in long-term memory seems to influence word recognition.
\end{abstract}

The early stages of the acquisition of reading skills require learning of the correspondence between the visual and auditory forms of verbal units, that is between letters and sounds (Ehri, 1995). Learning grapheme-to-phoneme conversion (GPC) rules requires the ability to perceive, segment and explicitly manipulate the sounds of spoken words, an ability generally referred to as phonological awareness, which calls for full awareness of the phonological structure of speech (Gombert, 1992; Stuart, 2005). When decoding a word, the sequence of phonemes resulting from GPC has to be held in some form of short-term buffer in order to be assembled and then matched to phonological lexical representations stored in long-term memory, each step relying on phonological memory (Gathercole, 1995). Phonological awareness and phonological 
memory are both essential to the acquisition of reading skills (Ellis, 1990). However, while the former seems to have a bidirectional relationship with reading acquisition (Wagner, Torgesen \& Rashotte, 1994), most studies suggest a causal relationship between phonological memory and the early acquisition of reading skills (Passenger, Stuart \& Terrell, 2000; Wagner \& Torgesen, 1987). Moreover phonological awareness and phonological memory are also closely related to each other (Passenger et al., 2000; Wagner \& Torgesen, 1987). The complex interrelationships between phonological processes and the acquisition of reading skills raise the question of the development of phonological abilities shortly before and during the period of reading instruction. They also raise the question of their respective influence and predictive value on reading skills.

With respect to the development of phonological awareness, studies involving language-impaired children evidenced the necessity of reliable phoneme discrimination (Joanisse \& Seidenberg, 1998). Indeed the misperception of phonemes prevents the development of well-specified phonological representations and consequently may result in phonological deficits. So far, studies on the development of phonological abilities in normal developing children have not investigated the contribution of the early perceptual stage of phonological processing.

Most of the studies focusing on phonological awareness development agree that this ability increases significantly over the last months of kindergarten attendance and through the beginning of formal schooling (Lonigan, Burgess \& Anthony, 2000; Martin, Claydon, Morton, Binns \& Pratt, 2003; Stainthorp \& Hughes, 1998; Wagner, Torgesen, Laughon, Simmons \& Rashotte, 1993). Whereas children develop phonological abilities very early, before formal schooling, the awareness of phonological units and structural rules of speech appears later, and seems to emerge only when intentional control of phonological knowledge is required (Duncan, Seymour \& Hill, 1997). Similarly, some degree of rhyme and syllable awareness is present around the age of 4, but the emergence of phonemic awareness seems contingent upon the acquisition of reading skills (De Loureiro et al., 2004; Stainthorp \& Hughes, 1998; Ziegler \& Goswami, 2005). Reading instruction seems therefore necessary to achieve phonological awareness, but at the same time phonological awareness is regarded as one of the key factors determining the acquisition of reading abilities (Morais, Bertelson, Cary \& Alegria, 1986). Indeed, it has been shown, across languages, that preliterate phonological skills played a significant role in subsequent reading achievements (Bryant, MacLean, Bradley \& Crossland, 1990; McBride-Chang \& Kail, 2002). Referring more specifically to phonemic awareness, it has been found to be among the best predictors of both word and nonword reading ability (Duncan et al., 1997; Hulme, 2002; Schatschneider, Fletcher, Francis, Carlson \& Foorman, 2004; Stuart, 2005; Swanson \& Alexander, 1997).

In comparison with the number of studies concerned with the role of phonological awareness, there have been fewer investigations that looked into the contribution of phonological memory to reading acquisition. In most of these studies phonological memory was assessed using nonword repetition and immediate serial recall tasks (Gathercole \& Baddeley, 1993). However, such tasks involve at the same time various, related components of phonological memory, such as (1) short-term memory (STM) capacity, (2) long-term phonological knowledge and (3) memory for serial order. STM typically refers to the capacity to store material over brief periods of time, and can be appraised by manipulating the number of items to be recalled (Gathercole \& Adams, 1994). Long-term phonological knowledge can be evidenced, for example, through the phonotactic frequency effect, that is better recall rates for nonwords that mimic existing 
phonological structures (Gathercole \& Adams, 1994; Majerus \& van der Linden, 2003). The memory for serial order (i.e. the order in which items are presented), which is generally assessed using serial-order recognition or reconstruction tasks, seems to be distinct from the memory for item information. A recent theoretical and experimental body of work suggests that the retention of item- and order-related information is related to distinct cognitive processes. Indeed, item-related information relies partly on the temporary activation of the language network, while order-related information is processed by a more specific STM system (Burgess \& Hitch, 1999; Majerus, Poncelet, Elsen \& van der Linden, 2006). Furthermore, some models assume a direct link between the serial-order STM system and sub-lexical levels of phonological representation (Gupta, 2003).

The multiple components involved in phonological memory may explain its slow development (Wagner et al., 1994). Indeed, the phonological memory capacity is thought to dramatically increase between 4 and 12 years of age, in relation with increasing verbal resources (Alloway, Gathercole \& Pickering, 2006; Gathercole, 1998). Subvocal repetition, increasing the amount of information that can be retained in an STM task, starts to appear at 7 years of age, and increased vocabulary and phonological knowledge is also instrumental in improving memory performance until adulthood (Gathercole, 1998). To the best of our knowledge, the development of the various phonological memory components has not yet been investigated simultaneously.

Although phonological memory has been found to be involved in the acquisition of reading skills, it has mostly been studied through nonword repetition tasks, which does not help dissociate the influence of the various STM components (Gathercole, 1995; Passenger et al., 2000). Although recent studies have evaluated the relative contribution of the various components of phonological memory to the learning of new words in adults, no study has compared their influence on the acquisition of reading skills (Gupta, 2003; Majerus et al., 2006). Among the various STM components, only subvocal rehearsal has been investigated and found to correlate with reading abilities (Gray \& McCutchen, 2006). As far as the other components have not yet been accounted for, one cannot distinguish the respective contribution of STM capacity, memory for serial-order information and long-term phonological knowledge to the acquisition of reading skills.

Phonological awareness and phonological memory were found to be both associated with reading skills, but also closely related to each other (for a review, see Wagner \& Muse, 2006). One potential explanation for this relationship might be the verbal memory load required in many tasks designed to measure phonological awareness (Alloway, Gathercole, Willis \& Adams, 2004). Alternatively, verbal memory tasks demand phonological processing to store verbal material into a phonological code (Gathercole, Packiam-Alloway, Willis \& Adams, 2006). To date, three hypotheses have been put forward to account for this relationship (Alloway et al., 2004; Gathercole, Tiffany, Briscoe \& Thorn, 2005). The first considers that phonological awareness and phonological memory both capitalise on common phonological processing substrate (Dufva, Niemi \& Voeten, 2001; Griffiths \& Snowling, 2002). The second suggests that they are distinguished in that phonological awareness relies on knowledge about the phonological structure of speech, whereas phonological memory relies on the quality of underlying phonological representations (Windfuhr \& Snowling, 2001). According to the third hypothesis, phonological awareness and memory are both constrained by the efficiency of phonological processing, but they also utilise distinct mechanisms based on phonological knowledge and the phonological loop, respectively (Alloway et al., 2004; De Jong \& Van der Leij, 1999; Gathercole et al., 2005, 2006). The results of developmental studies suggest that while phonological awareness and 
memory tend to be regarded as related to a single phonological ability in young children, they become distinct during development, especially between kindergarten and the first grades of primary school (Passenger et al., 2000; Wagner et al., 1994; Wagner, Torgesen \& Rashotte, 1999). Therefore, as this relationship seems to evolve during development, the experimental data tend to corroborate the hypothesis of two distinct abilities originating from a common phonological ground (De Jong \& Van der Leij, 1999).

Despite the growing number of studies being simultaneously interested in phonological awareness and phonological memory, it remains still to specify the nature of the relationship between these two phonological processes and also to clarify their respective contributions to early reading skills. In fact due to relationships between phonological memory and phonological awareness, there should be no independent contribution between phonological memory and early reading achievement, as the contribution of phonological memory to reading abilities may be mediated by phonological awareness (Naslund \& Schneider, 1996).

Before becoming interested in the respective contributions of these two phonological skills to reading achievement, it seemed to us necessary to study their development over the early school years. For this purpose, children were tested just before and through the early stages of reading acquisition with a series of tasks designed to appraise each step of phonological processing. Hence, the first aim of this study was to specify the development of a range of phonological abilities (from the early perceptual step of phonological processing to phonological awareness, as well as phonological memory components) involved in learning to read. On the other hand, we attempted to investigate simultaneously various phonological memory components, including STM capacity, memory for serial order and influence of long-term phonological knowledge.

The second aim of the study was then to examine the respective influences of different aspects of phonological processing on early reading development. Because it has been shown that reading induces phonological refinement and that phonological skills play a prominent role through the earliest stages of reading acquisition, the first year of reading instruction seems to be the most critical period to distinguish the influence of different phonological processing on reading acquisition (Ehri, 1995; Ziegler \& Goswami, 2005). Considering phonological discrimination, awareness and memory as different steps of phonological processing instrumental in the acquisition of reading skills, we first hypothesised a close relationship between these processes, each depending on distinct mechanisms. Secondly we put forward that, behind the influence of phonological processing throughout the acquisition of reading skills, the various phonological processes would make distinct contributions to reading skills, at different stages of the learning process. More specifically, crucial for the segmentation of the words to be read, phonological awareness should become primarily involved at the very beginning of the instruction of GPC rules, and phonological memory, required to maintain accurate sequences of phonemes resulting from GPC, would be brought into play later.

\section{Method}

\section{Participants}

The study started with a group of 44 preschool children attending the last year at kindergarten before they received any formal reading instruction. As 10 children left the school, only 34 were tested a second time at the end of the first grade. Their age at the 
beginning of the study ranged from 5.3 to 6.4 years $(m=5 ; 10 \pm 3 \mathrm{~m})$. Their nonverbal reasoning ability was above the 50th percentile, as measured by the Raven's Progressive Matrice PM47 picture completion task (Raven, 2000). The children had no noticeable visual, auditory, articulatory or neurological deficit. Prior informed consent was obtained from the parents.

\section{Phonological processing assessment}

The phonological tasks were performed twice. The first administration occurred at the end of the last year at kindergarten just before the children were introduced to reading, and the second one at the end of the first grade, after 8 months of reading instruction. The children were tested individually by a trained experimenter, and except for practice trials, they did not receive any feedback. Each test was administered over four sessions to facilitate optimal performance on all tasks. The duration of each session was 30 minutes.

Perceptual phonological discrimination. The phonological discrimination task consisted of 124 pairs of CV $(n=64)$ or CCV $(n=60)$ syllables with an inter-stimulus interval of $250 \mathrm{~ms}$ : 62 'identical' pairs (e.g. /bYa///bYa/) and 62 'different' pairs (e.g. / ta/-/da/; Van Reybroeck, 2003). The initial consonant of the 'different' pairs varied by one phonetic feature (voicing or place of articulation) while the vocalic context was kept constant for all pairs $(/ \mathrm{a} /)$. The items, pronounced by a trained female native speaker of French, were presented through headphones and the children were asked to answer orally after each trial whether the two syllables were identical or different.

Phonological awareness. The phonological awareness assessment relied on a commonunit judgement task involving three levels of speech processing: rhyme, syllable and phoneme. Two pictures were presented on a computer screen. The children had to decide whether the nouns corresponding to the objects on the two pictures had one common speech segment, and answer by pressing one of two keys of the keyboard, coloured in green for 'yes' and red for 'no'. In the rhyming judgement task, the subjects had to decide whether or not the picture names rhymed (e.g. / I $\underline{u} /$ - /Gu/ vs /nwA/ - /fV/). In the common syllable or phoneme task, they were asked to determine whether two picture names had one common syllable (e.g. /tomat/ - /moto/ vs /kamjt/ - /sizo/) or phoneme (e.g. / $\underline{b} C t /$ - /kyb $/$ vs /pyl/ - / $/ \mathrm{rCb} /$ ), respectively. Each task comprised 4 practice and 24 experimental trials, with an equal number of yes and no responses. In order to avoid a confounding effect of picture recognition and/or naming, the pictures were named by the examiner. The picture names were frequent monosyllabic or disyllabic words with an age of acquisition of $<72$ months (Alario \& Ferrand, 1999).

Phonological STM. Phonological STM was assessed through three different tasks designed to measure STM components, such as memory for item, for serial order and the influence of long-term phonological knowledge. Two repetition and one recognition tasks were run under E-prime (Psychological Software Tools, Pittsburgh, 2000). The stimuli were recorded by a trained female native speaker of French, digitised and edited into individual files. They were presented binaurally via headphones connected to a laptop computer. In the repetition tasks, the responses were recorded using a microphone and transcribed for subsequent scoring by two independent evaluators, with regard to accuracy of recall. Correlation analyses showed a significant inter-rater agreement for 
each repetition task (nonword repetition, $r=.82, p<.00001$ and immediate serial recall, $r=.74, p<.00001)$.

Immediate serial recall (ISR) of nonword lists. The first STM task was an immediate serial recall task involving nonword lists, to assess the influence of sub-lexical phonological knowledge and of sequence length. Twenty high-phonotactic-frequency (HF, mean frequency: 1544) and 20 low-phonotactic-frequency (LF, mean frequency: 269) CVC nonwords were presented in lists comprising one to four items, with two trials per length. The phonotactic frequencies were determined using the French phonetic database by Tubach and Boë (1990). A total of 16 lists were presented, that is four pairs of lists with an identical number of items, for each phonotactic frequency. The children were requested to listen to and repeat each list of nonwords.

Single nonword repetition task. In order to assess phonological STM and check for a possible effect of long-term phonological knowledge on STM, two lists of 30 nonwords (one with CVC and another with CVCCVC strings) were presented for the children to repeat. Each list contained an equal number of nonwords including HF (mean frequency: 808) and LF (mean frequency: 126) diphones (e.g.: HF / tTf/ - LF/tVf/ for CVC strings; HF /badmaf/ - LF : /fummyv/ for CVCCVC strings); HF and LF nonwords were matched for spoken duration.

Recognition of the serial order of digits. The task was used to assess the memory for serial order and the effect of sequence length. The children were presented with two lists of digits and, immediately after, had to decide whether or not the order of the digits was identical in the two lists (e.g. list $1: 2-3-1$; list $2: 2-3-1$ vs list $1: 3-2-1$; list $2: 2-3-1$ ) by pressing the 'yes' or 'no' key. The length of the lists ranged from two to four items. There were 6 trials per sequence length, totalling 18 trials.

\section{Lexical and reading abilities}

Lexical abilities were assessed at each schooling level through the French version of the Peabody test (Dunn, Thériault-Whalen \& Dunn, 1993).

Reading abilities were assessed at the end of first grade, through two different tasks, evaluating, respectively, decoding abilities and word recognition. Decoding abilities were evaluated using the standardised French reading test 'L'Alouette' (Lefavrais, 1967). In this test, children read a nonsensical text, in which the absence of meaning prevented the reliance on a context and forced them to resort to decoding. The total number of words correctly decoded within 3 minutes was entered in the statistical analyses. Word recognition was assessed by means of a word-to-picture matching task, in which children had to state whether or not a written word matched with a picture (Khomsi, 1990). They were presented with 50 pairs of pictures and words, of which 20 were matching and 30 non-matching pairs. The children performed the task after five practice trials.

\section{Results}

\section{Development of different phonological abilities}

The first purpose of the study was to examine improvement over time of the performance on a series of phonological tasks. Accordingly, a series of multivariate analyses of variance (MANOVAs) was performed on each set of measurements (phonological discrimination, phonological awareness, phonological memory) using the schooling level 
as repeated measure. Before entering the data in the statistical analyses we checked that the responses obtained in each forced-choice task (i.e. phonological discrimination and awareness tasks and serial-order recognition task) were significantly different from chance. The means and standard deviations for all measurements obtained at kindergarten and at the end of first grade are provided in Table 1.

Perceptual phonological discrimination. The MANOVA, performed on the mean scores of phonological discrimination task with schooling level and type of syllable pairs (identical and different) as within-subject factors, showed a significant main effect of schooling level, $F(1,31)=31.5, p<.0001$. As shown in Table 1 , the mean performance on the phonological discrimination test increased between kindergarten and first grade. The analysis revealed a near significant interaction of Schooling Level $\times$ Syllable Pair type, $F(1,31)=3.63, p<.06$. The Newman-Keuls test showed that the improvement of performance was higher for different than for identical pairs $(p<.05)$, and that the difference between identical and different syllable pairs, significant at kindergarten $(p<.05)$, was no longer significant at the end of first grade $(p>.05)$.

Phonological awareness. The MANOVA performed on the mean scores of phonological awareness tasks revealed a significant main effect of schooling level $F(1,33)=10.6$,

Table 1. Performance for each task at each session $(N=34)$.

\begin{tabular}{|c|c|c|c|c|c|c|c|c|}
\hline \multirow[t]{2}{*}{ Task } & \multicolumn{4}{|c|}{ Kindergarten } & \multicolumn{4}{|c|}{ First grade } \\
\hline & $M$ & $S D$ & $\begin{array}{c}\text { Range } \\
\text { (minimum- } \\
\text { maximum) }\end{array}$ & $\begin{array}{c}\% \text { children } \\
>90 \%\end{array}$ & $M$ & $S D$ & $\begin{array}{c}\text { Range } \\
\text { (minimum- } \\
\text { maximum) }\end{array}$ & $\begin{array}{c}\% \text { children } \\
>90 \%\end{array}$ \\
\hline \multicolumn{9}{|c|}{ Phonological discrimination (\%) } \\
\hline Similar & 78.9 & 15.2 & $50-98$ & 8.8 & 87.3 & 10.5 & $58-100$ & 11.8 \\
\hline Different & 69.8 & 19.8 & $13-95$ & 2.9 & 84.2 & 15.7 & $37-98$ & 26.5 \\
\hline \multicolumn{9}{|c|}{ Phonological awareness (\%) } \\
\hline Rhyme & 82.5 & 17 & $38-100$ & 26.5 & 84.9 & 12.4 & $58-96$ & 20.6 \\
\hline Syllable & 73.7 & 16.6 & $45-96$ & 5.9 & 79.2 & 14.5 & $54-96$ & 5.6 \\
\hline Phoneme & 73.8 & 15.8 & $41-92$ & 5.9 & 82.6 & 13.8 & $42-96$ & 17.7 \\
\hline \multicolumn{9}{|c|}{ Immediate serial recall (\%) } \\
\hline \multicolumn{9}{|l|}{ HF nonwords } \\
\hline 1-item list & 88.6 & 19.9 & $50-100$ & 70.6 & 98.5 & 8.6 & $50-100$ & 97.1 \\
\hline 2-item list & 58.3 & 31.6 & $0-100$ & 20.6 & 76.5 & 30.7 & $0-100$ & 58.8 \\
\hline 3-item list & 9.1 & 16.3 & $0-50$ & 0 & 23.5 & 28.1 & $0-100$ & 2.9 \\
\hline 4-item list & 3 & 12.1 & $0-50$ & 0 & 4.4 & 14.4 & $0-50$ & 0 \\
\hline \multicolumn{9}{|l|}{ LF nonwords } \\
\hline 1-item list & 82.8 & 25 & $0-100$ & 52.9 & 98.5 & 8.6 & $50-100$ & 97.1 \\
\hline 2-item list & 56.1 & 31.3 & $0-100$ & 14.7 & 63.2 & 33.3 & $0-100$ & 38.2 \\
\hline 3-item list & 14.4 & 18.7 & $0-50$ & 0 & 36.8 & 39.5 & $0-100$ & 20.6 \\
\hline 4-item list & 7.4 & 18 & $0-50$ & 0 & 0.0 & 0.00 & $0-0$ & 0 \\
\hline \multicolumn{9}{|c|}{ Recognition of the serial order of digits (\%) } \\
\hline 2-item list & 85.8 & 20.9 & $33-100$ & 58.8 & 86.3 & 19.4 & $50-100$ & 55.9 \\
\hline 3-item list & 77.9 & 25.2 & $0-100$ & 41.2 & 88.2 & 19.9 & $33-100$ & 67.7 \\
\hline 4-item list & 59.3 & 22.5 & $0-100$ & 8.8 & 75.5 & 21.8 & $17-100$ & 29.4 \\
\hline \multicolumn{5}{|c|}{ Decoding abilities (number of correctly read words) } & 58.7 & 36.7 & $9-166$ & - \\
\hline \multicolumn{5}{|c|}{ Word recognition $(\%)$} & 78.3 & 9.5 & $58-84$ & - \\
\hline
\end{tabular}


$p<.01$, and speech segment, $F(2,66)=4.3, p<.05$ but no significant interaction between schooling level and speech segment, $F(2,66)=1.62$, $n s$. As expected, the children performed significantly better on the phonological awareness task in the first-grade testing. A Newman-Keuls test evidenced better achievements in the rhyming judgement task $(p<.05)$ than in the common syllable or phoneme judgement task $(p>.05)$.

\section{Phonological STM}

Immediate serial recall of nonword lists. As, in the first-grade tests, the correct recall rate exceeded $95 \%$ for 1 -item sequences, and since a great majority of children failed to recall any 4-item sequence, only the performance registered for 2- and 3-item sequences were considered in subsequent analyses. The MANOVA, performed with schooling level, list length and phonotactic frequency as within-subject factors yielded a significant main effect of schooling level, $F(1,31)=18.4, p<.001$ and list length, $F(1,31)=103.3, p<.0001$, and a Significant List Length $\times$ Phonotactic Frequency interaction, $F(1,31)=7.4, p<.01$. The children performed better in first grade. Post hoc analysis of significant interaction indicated that the list length effect was less pronounced for low- than for high-phonotactic-frequency nonwords $(p<.05)$. This was related to the better recall for low- than high-phonotactic frequency items for 3 -item lists $(p<.06)$ but no difference between low- and high-phonotactic frequency items for 2-item lists $(p>.05)$.

Single nonword repetition task. A MANOVA was performed on the mean scores of nonword repetition task with the schooling level, item length and phonotactic frequency as within-subject factors. A significant effect emerged for schooling level, $F(1,33)=64.6, p<.0001$. As shown in Figure 1, the mean performance on the repetition task increased between the two testing sessions. The Schooling Level $\times$ Item Length, $F(1,33)=14.7, \quad p<.01$, Schooling Level $\times$ Phonotactic Frequency, $F(1,33)=5.8$, $p<.05$ and Schooling Level $\times$ Item Length $\times$ Phonotactic Frequency, $F(1,33)=7.4$, $p<.01$ interactions were also significant (Figure 1). A Newman-Keuls test indicated, firstly, a larger effect of item length and phonotactic frequency on kindergarten results than on first-grade results $(p<.05)$, and secondly, a more pronounced increase $(p<.05)$ in performance between the two schooling levels for the repetition of disyllabic nonwords and more specifically those with a low phonotactic frequency.

Recognition of the serial order of digits. A MANOVA was performed on the mean scores of recognition of the serial-order task using schooling level and list length as within-subject factors. The results showed a significant main effect of schooling level, $F(1,33)=7.3, p<.05$, and list length, $F(2,66)=25.9 p<.0001$ and a significant Schooling Level $\times$ List Length interaction, $F(2,66)=4.4, p<.05$. The Newman-Keuls test revealed a significant increase in performance between the two schooling levels for 3 - and 4-item lists $(p<.05)$, but not for 2-item lists $(p>.05)$. Moreover, while performance measured at kindergarten was significantly different for each list length, in the first grade only the results achieved with 4-item lists were significantly lower than those achieved with 2- and 3-item lists.

In summary, the children showed large improvements in their performances covering the whole phonological tasks between kindergarten and first grade of primary school. In spite of an apparent lower variability, the performance on phonological discrimination and phonological awareness tasks obtained at first grade were not at ceiling. A few children obtained a performance $>90 \%$ on one or other of these tasks (Table 1). There was sufficient variability on these measurements to allow us to examine how they were related to other measures and particularly to measures of reading attainment. 

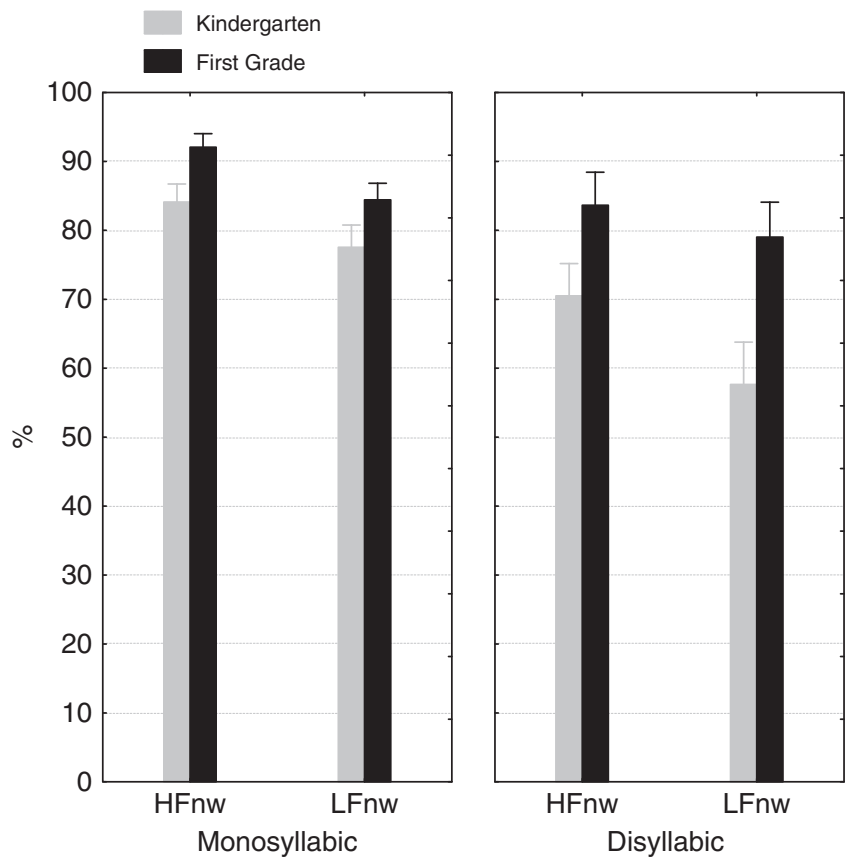

Figure 1. Percentage (and standard deviation) of correct responses in the nonword repetition task. Note: HFnw: high-phonotactic-frequency nonword; LFnw: low-phonotactic-frequency nonword.

\section{Phonological skills as predictors of early reading}

The second purpose of our longitudinal study was to investigate the predictive value of different aspects of phonological abilities on early reading skills. Accordingly, hierarchical multiple regression analyses were performed. Before reporting these analyses, it is informative to describe the pattern of concurrent and longitudinal correlations obtained between the measures.

Partial correlation analyses. Partial correlation analyses (controlling for nonverbal intelligence) were conducted in order to examine (a) the interrelationships between the phonological tasks at each schooling level and between the two grades, and (b) the interrelationships between the phonological abilities and reading achievement. The analyses were carried out using the overall percentage of correct responses in each task. The correlation coefficients between all these measurements are shown in Table 2.

The performance on each phonological task measured at kindergarten correlated highly with the performance measured in first grade.

At kindergarten, phonological discrimination correlated strongly with phonological awareness $(r=.40)$, but not with phonological memory (with the exception of the serialorder recognition task, $r=.39$ ). Phonological discrimination and phonological awareness were also correlated with subsequent reading abilities (ranging from .32 to .60). Conversely, the correlations between phonological memory and reading skills were not significant.

Stronger correlations (ranging from .34 to .65) were found between first-grade measurements than between kindergarten measurements. In particular, at the end of first grade, the performance on phonological memory tasks strongly correlated with each other and with 
Table 2. Correlations between phonological and reading scores $(N=34)$.

\begin{tabular}{|c|c|c|c|c|c|c|c|c|c|c|}
\hline & \multicolumn{5}{|c|}{ Kindergarten } & \multicolumn{5}{|c|}{ First grade } \\
\hline & 1.1 & 1.2 & 1.3 & 1.4 & 1.5 & 2.1 & 2.2 & 2.3 & 2.4 & 2.5 \\
\hline \multicolumn{11}{|l|}{ Kindergarten } \\
\hline 1.1 Phonological discrimination & - & & & & & & & & & \\
\hline 1.2 Phonological awareness & 0.40 & - & & & & & & & & \\
\hline 1.3 Nonword repetition & 0.18 & 0.36 & - & & & & & & & \\
\hline 1.4 Immediate serial recall & 0.07 & 0.25 & 0.51 & - & & & & & & \\
\hline 1.5 Serial order recognition & 0.39 & 0.24 & 0.16 & 0.07 & - & & & & & \\
\hline \multicolumn{11}{|l|}{ First grade } \\
\hline 2.1 Phonological discrimination & 0.56 & 0.48 & 0.24 & 0.05 & 0.51 & - & & & & \\
\hline 2.2 Phonological awareness & 0.18 & 0.62 & 0.38 & 0.34 & 0.12 & 0.34 & - & & & \\
\hline 2.3 Nonword repetition & 0.39 & 0.36 & 0.48 & 0.61 & 0.37 & 0.24 & 0.36 & - & & \\
\hline 2.4 Immediate serial recall & 0.47 & 0.61 & 0.41 & 0.49 & 0.32 & 0.50 & 0.46 & 0.65 & - & \\
\hline 2.5 Serial order recognition & 0.48 & 0.51 & 0.48 & 0.31 & 0.45 & 0.54 & 0.44 & 0.40 & 0.43 & - \\
\hline \multicolumn{11}{|l|}{ Reading abilities } \\
\hline 2.6 Decoding ability & 0.37 & 0.49 & 0.25 & 0.25 & 0.00 & 0.40 & 0.31 & 0.21 & 0.30 & 0.54 \\
\hline 2.7 Word recognition & 0.32 & 0.60 & 0.28 & 0.20 & 0.00 & 0.28 & 0.28 & 0.08 & 0.41 & 0.36 \\
\hline
\end{tabular}

Note: Coefficients in bold are significant at $p<.05$, and italicised coefficients have a $p$-level between .05 and .1.

phonological discrimination and awareness skills. It is notable that in first grade, the performance on the immediate serial recall and the serial-order recognition tasks correlated strongly with word recognition and decoding abilities, respectively (ranging from .36 to .54). By contrast, the correlations between phonological awareness performance and decoding abilities $(r=.31)$ were lower than those observed at kindergarten $(r=.49)$.

Finally, one may underline the absence of correlation between nonword repetition and reading ability measurements. This might be related to the design of the task, which involved monosyllabic and disyllabic nonwords. Most nonword repetition tasks usually involve items with up to five syllables, even when they are intended for 5-year-old children (Gathercole, 1995).

Hierarchical regression analyses. Given the high degree of intercorrelations among the different phonological measurements at kindergarten or in first grade (except nonword repetition), it was important to establish which phonological components independently predicted reading scores. In other words, we attempted to determine their respective influence on the acquisition of reading skills. Accordingly, parallel sets of hierarchical multiple regression analyses were carried out to examine the independent contribution of phonological discrimination, awareness and memory to reading achievements, with either decoding abilities or word recognition as the dependent variable. Because of the relatively small size of the sample and the large potential number of predictor variables, it was necessary to limit the number of variables entered into each regression equation. Accordingly, only predictor variables, which correlated with the dependent variables at the .05 level, were included. In each analysis, nonverbal intelligence was entered at Step 1 and vocabulary at Step 2, to control for individual differences in the children's nonverbal efficiency and vocabulary level. Phonological discrimination, phonological awareness or phonological memory were then entered in alternating order at Steps 3, 4 or 5 to assess their relative importance in the prediction of reading ability. In this way, all the variance due to extraneous variables was accounted for and thus, if the last step accounts for a 
significant amount of the variance, one can be sure that there is a genuine link between predictor variables and the reading achievements. The outcomes of the multiple regression analyses are summarised in Tables $3,4 \mathrm{a}$ and $4 \mathrm{~b}$.

First, one may underline that no analysis indicated a significant contribution of nonverbal intelligence or vocabulary level to either decoding or word recognition abilities.

Regression analyses between phonological discrimination and phonological awareness at kindergarten and reading skills in first grade. As previously stated, only phonological discrimination and phonological awareness scores correlated with the reading measurements (Table 2). A set of hierarchical regressions assessed their relative contribution to reading abilities (Table 3). Together these variables accounted for $38-40 \%$ of the variance in reading performance. But only phonological awareness made an independent contribution when entered at the last step. With phonological discrimination entered at Step 3, phonological awareness accounted for $20 \%$ of variance in decoding abilities and $24 \%$ in word recognition. When the two measurements were entered in reverse order, phonological discrimination made a near significant contribution to decoding, but made no independent contribution to word recognition.

Regression analyses between phonological variables, verbal memory and reading abilities, in first grade. Phonological discrimination, phonological awareness and serial-order recognition scores were correlated with decoding abilities in the first grade (Table 2). These three measurements were entered in a set of hierarchical multiple regressions (Table 4a). Altogether these variables accounted for $38 \%$ of the variance in decoding abilities. When entered at the last step, only serial-order recognition made a near significant independent contribution, accounting for $8 \%$ of the variance in decoding abilities. By contrast, phonological discrimination or phonological awareness made no independent contribution to decoding abilities.

As previously underlined, immediate serial recall and serial-order recognition scores were correlated with word recognition performance (Table 2). A final set of hierarchical multiple regressions was conducted with nonverbal intelligence, vocabulary level, immediate serial recall and serial-order recognition (Table 4b). Considered together, they accounted for $28 \%$ of the variance. But only immediate serial recall made an independent contribution when entered at Step 4. With serial-order recognition entered at Step 3, immediate serial recall accounted for $15 \%$ of the variance in word recognition performance. By contrast, serial-order recognition made no independent contribution to word recognition.

Table 3. Hierarchical multiple regression analyses of the predictors of decoding ability and word recognition.

\begin{tabular}{lllllll}
\hline Step & Variable & \multicolumn{2}{c}{ Decoding ability } & & \multicolumn{2}{c}{ Word recognition } \\
\cline { 3 - 4 } \cline { 5 - 6 } & & $R^{2}$ change & $p$ & & $R^{2}$ change & $p$ \\
\hline 1. & Nonverbal intelligence & .06 & $n s$ & & .08 & $n s$ \\
2. & Vocabulary & .00 & $n s$ & .02 & $n s$ \\
3. & KG phonological discrimination & .12 & .02 & .06 & .08 \\
4. & KG phonological awareness & .20 & .007 & .24 & .002 \\
3. & KG phonological awareness & .27 & .002 & & .25 & $n s$ \\
4. & KG phonological discrimination & .06 & .059 & & .05 & \\
\hline
\end{tabular}

Note: KG, kindergarten. 
Table 4a. Hierarchical multiple regression analyses of the predictors of decoding abilities.

\begin{tabular}{|c|c|c|c|}
\hline \multirow[t]{2}{*}{ Step } & \multirow[t]{2}{*}{ Variable } & \multicolumn{2}{|c|}{ Decoding abilities } \\
\hline & & $R^{2}$ change & $p$ \\
\hline 1. & Nonverbal intelligence & .06 & $n s$ \\
\hline 2. & Vocabulary & .00 & $n s$ \\
\hline 3. & 1G phonological discrimination & .18 & .01 \\
\hline 4. & $1 \mathrm{G}$ phonological awareness & .05 & $n s$ \\
\hline 5. & $1 \mathrm{G}$ serial-order recognition & .08 & .066 \\
\hline 3. & $1 \mathrm{G}$ phonological awareness & .11 & .057 \\
\hline 4. & $1 \mathrm{G}$ phonological discrimination & .13 & .03 \\
\hline 5. & $1 \mathrm{G}$ serial-order recognition & .08 & .066 \\
\hline 3. & $1 \mathrm{G}$ serial-order recognition & .24 & .002 \\
\hline 4. & $1 \mathrm{G}$ phonological discrimination & .05 & $n s$ \\
\hline 5. & $1 \mathrm{G}$ phonological awareness & .02 & $n s$ \\
\hline
\end{tabular}

Note: $1 \mathrm{G}$, first grade.

Table 4b. Hierarchical multiple regression analyses of the concurrent predictors of word recognition ability.

\begin{tabular}{|c|c|c|c|}
\hline \multirow[t]{2}{*}{ Step } & \multirow[t]{2}{*}{ Variable } & \multicolumn{2}{|c|}{ Word recognition } \\
\hline & & $R^{2}$ change & $p$ \\
\hline 1. & Nonverbal intelligence & .07 & .01 \\
\hline 2. & Vocabulary & .01 & $n s$ \\
\hline 3. & $1 \mathrm{G}$ immediate serial recall & .19 & .01 \\
\hline 4. & $1 \mathrm{G}$ serial-order recognition & .01 & $n s$ \\
\hline 3. & $1 \mathrm{G}$ serial-order recognition & .05 & $n s$ \\
\hline 4. & $1 \mathrm{G}$ immediate serial recall & .15 & .01 \\
\hline
\end{tabular}

Note: $1 \mathrm{G}$, first grade.

\section{Discussion}

This study was designed to specify, before and over the first year of reading instruction, the development of phonological processes, ranging from perceptual discrimination to phonological awareness and phonological memory, and to address the issue of their common or independent contributions to reading acquisition. Only longitudinal studies make it possible to determine the predictive value of various measurements in reading skills. However, beyond the primary interest of any longitudinal study, its main drawback is the risk of a decrease in the sample between the testing sessions. Indeed, here we report the data of only 34 out of the 44 children involved at the beginning of the study.

\section{Quantitative and qualitative developmental changes in phonological processes}

Our results showed that, in general, performance in the different phonological processing tasks increased consistently over a 1-year period spanning the final months at kindergarten and the first year of reading instruction. This improvement appears to involve all levels of phonological processing under investigation here. Even perceptual discrimination of syllables, the earliest ability to be established and to be required for phonological processing, was found to improve significantly over the first grade. Given that accurate phonemic perceptual discrimination is a prerequisite for phonemic 
awareness, the fact that it was not yet completely mastered by the children in this study might explain, at least partly, the poor performance in phoneme detection observed both at kindergarten and at the end of first grade.

Phonological awareness, as a whole, was found to have improved over first grade, corroborating previous findings (Wagner et al., 1993). If we examine the results as a function of the speech segments to be detected, our results show a better performance for the detection of rhyme than syllables or phonemes. With regard to syllables, our result may be explained by the French intonational structure of speech, characterised by the lengthening of the ending of words (Ladefoged, 1958). This peculiarity makes the final segment, and consequently the rhyme, more salient in French than in English or German, in which syllables have been found to be the earliest and easiest speech unit for children to detect (Naslund \& Schneider, 1996; Ziegler \& Goswami, 2005). With respect to the poor performance on the detection of a common phoneme, found at both schooling levels, this is in agreement with previous studies, showing that despite the development of phoneme detection over the first year of reading instruction, it generally takes longer to be mastered and induces more mistakes, even at the end of first grade (Liberman, Shankweiler, Fischer \& Carter, 1974). This finding is also in line with the assumption that the development of phonemic awareness depends at least partially on literacy (De Loureiro et al., 2004; Ziegler \& Goswami, 2005).

In the present study, several tasks were used to investigate various components of phonological memory such as general STM storage capacity, STM for serial order and the impact of long-term phonological knowledge. The results revealed a significant increase in performance for these components over the first grade. The list length by schooling-level interaction found in the nonword repetition and serial-order recognition tasks revealed a significantly increased memory capacity for both items and sequences. These results tend to confirm the developmental increase in STM capacity reported in previous studies (Gathercole, 1998; Majerus, Poncelet, Greffe \& van der Linden, 2006). Nevertheless one may wonder whether, behind this developmental improvement, the increase in the sequential component of STM could be related to reading instruction too. Indeed, to recognise a word, beginners have to hold in STM a sequence of phonemes resulting from GPC. Extensive practice of GPC rules from the beginning of first grade onwards might improve memory for sequences, which in turn might facilitate the storage of decoded phonological sequences, and consequently enable beginners to read, more easily, increasingly longer words.

Nonword repetition allowed us to assess the influence of long-term phonological knowledge, by contrasting performance related to high- and low-phonotactic-frequency nonwords. The results revealed lower performance in nonword repetition when lowphonotactic-frequency items were involved, yet at the same time, a more pronounced increase between the two schooling levels for low-phonotactic-frequency items. This pattern of results suggests, firstly, a deeper long-term phonological knowledge, and secondly, that the children take ever-increasing advantage of it as it develops. In addition, the increase in performance in the repetition of low-phonotactic-frequency nonwords, particularly pronounced for disyllables, indicates that the influence of long-term phonological knowledge combines with extended STM capacity.

Thus the overall improvement of phonological memory performance seems to be related to the developmental increase in STM capacity, memory for sequences and deeper long-term phonological knowledge. It is worth noting that the correlation analyses revealed that these three components of phonological memory were closely interrelated. 
Likewise, the correlations found between most of the phonological processes studied at the two schooling levels tend to confirm their common involvement in phonological processing (Wagner \& Torgesen, 1987; Wagner et al., 1993). Besides the continued involvement of phonological discrimination, the pattern of correlations seems to evolve over the first grade. First, the lack of correlation between phonological awareness and phonological memory scores measured at kindergarten provides substantial evidence for the independence of the two domains of phonological processing. However, it may also be the case that the independence of phonological awareness and phonological memory arises from the phonological judgement task used in our study. Thereafter, in first grade, phonological awareness appears conversely closely related to phonological memory. In summary, these results corroborate the hypothesis which views phonological awareness and memory as two separable phonological abilities though highly related (De Jong \& van der Leij, 1999; Gathercole et al., 2005). Indeed, our results suggest that phonological awareness and phonological memory skills relatively distinct in young children converge over first grade, as a consequence of their contribution to reading skills (Alloway et al., 2004). Moreover, phonological awareness and memory may be related through the ability of phonological discrimination as is suggested by the relationship between these three skills.

\section{Early influence of phonological awareness but later impact of phonological memory on reading skills}

Assuming that phonological awareness and phonological memory are related but distinct mechanisms, and considering the previously reported developmental evolution within phonological processing, we wondered whether predictions about reading achievements made on the basis of phonological awareness and phonological memory performance might evolve in the same way. The analysis of the correlations between reading abilities, such as decoding and word recognition, and performance on various phonological processing tasks, at kindergarten and in first grade, tend to reinforce this hypothesis. Indeed, reading abilities correlated mainly with performance in the phonological awareness task carried out at kindergarten, but with phonological memory achievements in first grade. To determine their independent contributions to reading acquisition, we carried out hierarchical regression analyses that allowed us to study the specific contributions of each phonological ability. Hierarchical regression analyses showed a specific contribution, at kindergarten schooling level, of phonological awareness to decoding ability and word recognition. In first grade, they showed a main contribution of serial-order recognition to decoding ability, and of nonword immediate serial recall to word recognition, while phonological awareness did no longer specifically contribute to either reading ability. These results may also provide helpful information for the understanding of the process of reading acquisition. The two phonological skills make separable contributions to success in the earliest stages of reading acquisition. At first and as we postulated before, phonological awareness seems to be crucial in the beginning of the instruction of letter-sound correspondences rules. Phonological memory, in contrast, may play a later role by maintaining the sequences of phonemes resulting from GCP. This stage of storage is necessary in order to gather these phonemes for identifying the word. So, as our results suggested, the roles of phonological awareness and phonological memory begin to differentiate during the learning of reading, though these two phonological skills remain highly correlated (Wagner \& Muse, 2006). 
Whereas numerous studies have already pointed out phonological awareness as one of the main predictors of the acquisition of reading skills (e.g. Schatschneider et al., 2004; Swanson \& Alexander, 1997), one important outcome of our study deals with the contribution of different aspects of phonological memory to reading acquisition. Serialorder memory appears as the most consistent predictor of decoding abilities. The contribution of serial-order recognition to decoding abilities could be related to the practice of GPC rules, which makes it necessary to hold in STM a sequence of phonemes in the requisite order (Gathercole, 1995). In the present study, the independent contribution of immediate serial recall to word recognition, even after controlling for serial-order recognition, implies a contribution of long-term phonological knowledge to word recognition. This might be related to the next step of the reading process, that is, matching an assembled sequence of phonemes with long-term phonological word representations.

Thus the influence on reading skills of serial-order STM memory and long-term phonological knowledge appears to supersede the early core influence of phonological awareness. They also appear to contribute to decoding and word recognition, respectively, which represent different aspects of reading. This confirms previous findings on the decreasing influence of phonological awareness on the development of reading skills (Bus \& van IJzendoorn, 1999). Our results suggest that at the early stage of the acquisition of reading skills, children noticeably increase their awareness of the phonological structure of speech, and subsequently have to memorise phonological information in both short- and long-term memory, and match it with pre-existing knowledge.

\section{Conclusion}

The three levels of phonological processing, that is, discrimination, awareness and memory, develop markedly during the period of acquisition of reading skills. Our results also confirm that they are all involved in a common phonological process, albeit through distinct mechanisms. Indeed, while phonological perceptual discrimination appears as a latent variable throughout the period studied here, the influence of phonological memory on the acquisition of reading skills seems to override that of phonological awareness, as children develop. Actually, while phonological awareness and knowledge relative to the phonological structure of speech make an early specific contribution to the acquisition of reading skills, the sequential component of STM makes a later, independent contribution to the decoding ability, and long-term phonological knowledge to word recognition.

\section{Acknowledgement}

We wish to thank Nathalie Heider for her help with linguistic corrections and the participants and their teachers for their time and commitment to the research.

\section{References}

Alario, F.X. \& Ferrand, L. (1999). A set of 400 pictures standardized for French: Norms for name agreement, image agreement, familiarity, visual complexity, image variability, and age of acquisition. Behavioral Research Methods, Instruments \& Computers, 31(3), 531-552.

Alloway, T.P., Gathercole, S.E. \& Pickering, S.J. (2006). Verbal and visiospatial short-term and working memory in children: Are they separable? Child Development, 77(6), 1698-1716. 
Alloway, T.P., Gathercole, S.E., Willis, C. \& Adams, A.M. (2004). A structural analysis of working memory and related cognitive skills in young children. Journal of Experimental Child Psychology, 87, 85-106.

Bryant, P., MacLean, M., Bradley, L.L. \& Crossland, J. (1990). Rhyme and alliteration, phoneme detection, and learning to read. Developmental Psychology, 26(3), 429-438.

Burgess, S.R. \& Hitch, G.J. (1999). Memory for serial order: A network model of the phonological loop and its timing. Psychological Review, 106(3), 551-581.

Bus, A.G. \& van IJzendoorn, M.H. (1999). Phonological awareness and early reading: A meta-analysis of experimental training studies. Journal of Educational Psychology, 91(3), 403-414.

De Jong, P.F. \& van der Leij, A. (1999). Specific contributions of phonological abilities to early reading acquisition: Results from a Dutch latent variable longitudinal study. Journal of Experimental Child Psychology, 91(3), 150-176.

De Loureiro, C S., Braga, L.W., Souza Ldo, N., Nunes Filho, G., Queiroz, E. \& Dellatolas, G. (2004). Degree of illiteracy and phonological and metaphonological skills in unschooled adults. Brain and Language, 89(3), 499-502.

Dufva, M., Niemi, P. \& Voeten, M.J.M. (2001). The role of phonological memory, word recognition, and comprehension skills in reading development: From preschool to Grade 2. Reading and Writing: An Interdisciplinary Journal, 14(1-2), 91-117.

Duncan, L.G., Seymour, P.H. \& Hill, S. (1997). How important are rhyme and analogy in beginning reading? Cognition, 63(2), 171-208.

Dunn, L.M., Thériault-Whalen, C.M. \& Dunn, L.M. (1993). Echelle de vocabulaire en images Peabody. Adaptation française du Peabody Picture Vocabulary Test Revised. Richmond Hill: Psycan.

Ehri, L.C. (1995). Phases of development in learning to read words by sight. Journal of Research in Reading, 18(2), 116-125.

Ellis, N. (1990). Reading, phonological skills and short-term memory: Interactive tributaries of development. Journal of Research in Reading, 13(2), 107-122.

Gathercole, S. \& Adams, A.M. (1994). Children's phonological working memory: Contributions of long-term knowledge and rehearsal. Journal of Memory and Language, 33(5), 672-688.

Gathercole, S. \& Baddeley, A. (1993). Working memory and language. Hove: Lawrence Erlbaum Associates.

Gathercole, S.E. (1995). Is nonword repetition a test of phonological memory or long-term knowledge? It all depends on the nonwords. Memory and Cognition, 23(1), 83-94.

Gathercole, S.E. (1998). The development of memory. Journal of Child Psychology and Psychiatry, 39(1), $3-27$.

Gathercole, S.E., Packiam-Alloway, T.P., Willis, C. \& Adams, A.M. (2006). Working memory in children with reading disabilities. Journal of Experimental Child Psychology, 93, 265-281.

Gathercole, S.E., Tiffany, C., Briscoe, J. \& Thorn, A. (2005). Developmental consequences of poor phonological short-term memory function in childhood: A longitudinal study. Journal of Child Psychology and Psychiatry, 46(6), 598-611.

Gombert, J. (1992). Metalinguistic development. Hemel Hempstead: Harvester Wheatsheaf.

Gray, A. \& McCutchen, D. (2006). Young readers' use of phonological information: Phonological awareness, memory, and comprehension. Journal of Learning Disabilties, 39(4), 325-333.

Griffiths, Y.M. \& Snowling, M.J. (2002). Predictors of exception word and nonword reading in dyslexic children: The severity hypothesis. Journal of Educational Psychology, 94, 34-43.

Gupta, P. (2003). Examining the relationship between word learning, nonword repetition, and immediate serial recall in adults. Quarterly Journal of Experimental Psychology A, 56(7), 1213-1236.

Hulme, C. (2002). Phonemes, rimes, and the mechanisms of early reading development. Journal of Experimental Child Psychology, 82(1), 58-64.

Joanisse, M.F. \& Seidenberg, M.S. (1998). Specific language impairment: A deficit in grammar or processing? Trends in Cognitive Science, 2(7), 240-247.

Khomsi, A. (1990). Epreuve d'évaluation de la compétence en lecture: lecture de mot et compréhension. Paris: ECPA.

Ladefoged, P. (1958). Syllable and Stress. Miscellanea Phonetics, 3, 1-15.

Lefavrais, P. (1967). Alouette. Paris: ECPA.

Liberman, I.Y., Shankweiler, D., Fischer, F.W. \& Carter, B. (1974). Explicit syllable and phoneme segmentation in the young child. Journal of Experimental Child Psychology, 18(2), 201-212.

Lonigan, C.J., Burgess, S.R. \& Anthony, J.L. (2000). Development of emergent literacy and early reading skills in preschool children: Evidence from a latent-variable longitudinal study. Developmental Psychology, 36(5), 596-613. 
Majerus, S., Poncelet, M., Elsen, B. \& van der Linden, M. (2006). Exploring the relationship between new word learning and short-term memory for serial order recall, item recall, and item recognition. European Journal of Cognitive Psychology, 18(6), 848-873.

Majerus, S., Poncelet, M., Greffe, C. \& van der Linden, M. (2006). Relations between vocabulary development and verbal short-term memory: The relative importance of short-term memory for serial order and item information. Journal of Experimental Child Psychology, 93(2), 95-119.

Majerus, S. \& van der Linden, M. (2003). Long-term memory effects on verbal short-term memory: A replication study. British Journal of Psychology, 21(2), 303-310.

Martin, F., Claydon, E., Morton, A., Binns, S. \& Pratt, C. (2003). The development of orthographic and phonological strategies for the decoding of words in children. Journal of Research in Reading, 26(2), 191-204.

McBride-Chang, C. \& Kail, R.V. (2002). Cross-cultural similarities in the predictors of reading acquisition. Child Development, 73(5), 1392-1407.

Morais, J., Bertelson, P., Cary, L. \& Alegria, J. (1986). Literacy training and speech segmentation. Cognition, 24(1-2), 45-64.

Naslund, J.C. \& Schneider, W. (1996). Kindergarten letter knowledge, phonological skills, and memory processes: Relative effects on early literacy. Journal of Experimental Child Psychology, 62(1), 30-59.

Passenger, T., Stuart, M. \& Terrell, C. (2000). Phonological processing and early literacy. Journal of Research in Reading, 23(1), 55-66.

Raven, J. (2000). The Raven's progressive matrices: Change and stability over culture and time. Cognitive Psychology, 41(1), 1-48.

Schatschneider, C., Fletcher, J.M., Francis, D.J., Carlson, C.D. \& Foorman, B.R. (2004). Kindergarten prediction of reading skills: A longitudinal comparative analysis. Journal of Educational Psychology, 96(2), 265-282.

Stainthorp, R. \& Hughes, D. (1998). Phonological sensitivity and reading: Evidence from precocious readers. Journal of Research in Reading, 21(1), 53-68.

Stuart, M. (2005). Phonemic analysis and reading development: Some current issues. Journal of Research in Reading, 28(1), 39-49.

Swanson, H.L. \& Alexander, J.E. (1997). Cognitive processes as predictors of word recognition and reading comprehension in learning-disabled and skilled readers: Revisiting the specificity hypothesis. Journal of Educational Psychology, 89(1), 128-158.

Tubach, J.L. \& Boë, L.J. (Eds.) (1990). Un corpus de transcription phonétique. Moulineaux, France: Telecom.

Van Reybroeck, M. (2003). Elaboration d'une batterie d'épreuves évaluant les compétences phonologiques. Masters Thesis, Brussels Free University.

Wagner, R.K. \& Muse, A. (2006). Short-term memory deficits in developmental dyslexia. In T.P. Alloway \& S.E. Gathercole (Eds.), Working memory and neurodevelopmental disorders. (pp. 41-57). New York: Psychology Press.

Wagner, R.K. \& Torgesen, J.K. (1987). The nature of phonological processing and its causal role in the acquisition of reading skills. Psychological Bulletin, 101(2), 192-212.

Wagner, R.K., Torgesen, J.K., Laughon, P., Simmons, K. \& Rashotte, C.A. (1993). Development of young readers' phonological processing abilities. Journal of Educational Psychology, 85(1), 83-103.

Wagner, R.K., Torgesen, J.K. \& Rashotte, C.A. (1994). Development of reading-related phonological processing abilities: New evidence of bidirectional causality from latent variable longitudinal study. Developmental Psychology, 30(1), 73-87.

Wagner, R.K., Torgesen, J.K. \& Rashotte, C.A. (1999). Comprehensive test of phonological processing. Austin, TX: Pro-Ed.

Windfuhr, K.L. \& Snowling, M. (2001). The relationship between paired associate learning and phonological skills in normally developing readers. Journal of Experimental Child Psychology, 80(2), 160-173.

Ziegler, J.C. \& Goswami, U. (2005). Reading acquisition, developmental dyslexia, and skilled reading across languages: A psycholinguistic grain size theory. Psychology Bulletin, 131(1), 3-29.

Christelle Nithart has a PhD in Developmental Neuropsychology. She is currently involved in the Laboratory of Imagery and Cognitive Neurosciences of Strasbourg University. Her research interest is in the field of language and reading acquisition in normal developing as well as in dyslexic and 
specific language impaired children. More specifically she studies the influence of phonological processes and serial order memory in reading acquisition and their disorders.

Elisabeth Demont received her PhD from the University of Dijon in 1994. She was Assistant Professor (1996-2004) then Professor in Developmental Psychology at the University of Strasbourg since 2004. She worked on reading development and reading disabilities in different populations. The main aim of her studies is to investigate the development and the contribution of phonological processing and/or working memory in reading disabilities. She collaborates on several projects with Marie-Noëlle Metz-Lutz. More recently, she leads a research with University of Montreal on the development of implicit learning.

Steve Majerus holds a PhD in Psychological Sciences from the University of Liege (1999) and is Research Associate at the Fonds de la Recherche Scientifique FNRS, Belgium. He has contributed more than 30 publications to international peer-reviewed journals. His research interests include interactions between language and memory in healthy subjects and patients with brain damage, neurodevelopmental disorders, functional neuroimaging of language and memory.

Martine Poncelet, $\mathrm{PhD}$, is currently an Assistant Professor and head of the Unit for Neuropsychology of Language and Learning in the Department of Cognitive Sciences at the University of Liège (Belgium). Her research interests are in the fields of dyslexia, bilingualism and aphasiology.

Jacqueline Leybaert has a $\mathrm{PhD}$ in Psychology (Université libre de Bruxelles) and is now Professor in Psychology and Speech therapy at the same University. She is a member of the LCLD (Laboratory Cognition Deafness and Development), where she conducts researches on deafness, cochlear implants, reading and spelling disorders, dyscalculia. She has written a number of journal papers and book chapters, mainly in the domain of deafness and phonological representations.

Marie-Noëlle Metz-Lutz received her MD degree from the University of Strasbourg Medical School and a Masters degree in linguistics from the Strasbourg University of Human Science in 1975. Specialising in neurological sciences, she is a Senior Scientist at the French Institute of Health and Medical Research (INSERM) since 1985. From 1994 to 2002, she led an INSERM research team on cognitive consequences of childhood epilepsy. In 2003 she joined a CNRS laboratory where her main research is about the neural bases of phonological processing in relation to language development and verbal learning in typical and atypical cognitive development.

Received 17 September 2009; revised version received 17 September 2009

Address for correspondence: Marie-Noëlle Metz-Lutz, Laboratoire d'imagerie et neurosciences cognitives, CNRS FRE 3289, Université de Strasbourg, France. E-mail: metzlutz@linc.u-strasbg.fr 